\title{
Mental Health Helper: Intelligent Mobile Apps in the Pandemic Era
}

\author{
Anggunmeka Luhur Prasasti, Iftitahrira Aulia Rahmi, Syarifah Faisa Nurahmani, Ashri \\ Dinimaharawati \\ School of Electrical Engineering, Telkom University, Bandung 40257, Indonesia
}

\begin{tabular}{l} 
ARTICLE INFO \\
\hline Article history: \\
Received October 21, 2021 \\
Revised December 11, 2021 \\
Accepted December 30, 2021 \\
\hline
\end{tabular}

\section{Keywords:}

Artificial Intelligence;

Expert System;

Mental Health;

Mobile Application

\begin{abstract}
Every human being faces various episodes of events that can cause changes in mental health conditions, including this coronavirus pandemic disease. The ups and downs of the psychological turmoil dynamics resulted, and also traumatic feelings can occur continuously or for a certain period. It can cause an adverse response for those who experience it and even cause anxiety or mental disorders. The implementation of restrictions on community activities during these pandemic circumstances makes people who want to check their mental health condition difficult to meet the experts or professionals such as psychologists. Therefore, the application that can detect these anxiety disorders as early as possible to minimize unwanted effects was developed. In the making of the application, an expert system is used to determine the results of the diagnosis. The expert system requires knowledge that is produced from experts, especially in the psychology field. The data that has been obtained will be processed and then yield the results determined from the classification of anxiety types using several methods in Artificial Intelligence. Several tests were carried out 50 times using Certainty Factor methods to obtain an accuracy rate of $96 \%$. It has similar accuracy compared to the Naïve Bayes method. This application called Mental Health Helper has a validity and reliability test to prove that this application is valid and reliable. It has better performance than previous researches, which still only has two classes of diseases.
\end{abstract}

This work is licensed under a Creative Commons Attribution-Share Alike 4.0

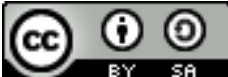

\section{Corresponding Author:}

Anggunmeka Luhur Prasasti, School of Electrical Engineering, Telkom University, Bandung 40257, Indonesia Email: anggunmeka@telkomuniversity.ac.id

\section{INTRODUCTION}

The coronavirus pandemic disease happening all over the world has changed everything. It does affect not only the financial condition but also the mental health condition of people [1]. Covid-19 has disrupted physical health as well as people's emotional equilibrium. This disease has already created, tense mental health system and led to the cause of disability worldwide. The impact on young to adult people has been particularly devastating, such as depression, symptoms of anxiety, and suicidal ideation [2]. The implementation of restrictions on community activities during these pandemic circumstances makes people who want to check their mental health condition difficult to meet the experts or professionals such as psychologists [3]. This growing issue of the Covid impact forced us to think of more creative approaches to overcome up any limitation's challenge.

Technology becomes another factor that contributes to mental health. An example is social media, where we can find various kinds of things, both positive and negative. Social media displays a lot of knowledge, insight, and even people's lives. The difference in lifestyles can affect mindsets and psychological conditions where there is a mindset to create expectations to have what other people have, such as lifestyles, possessions, and others [4].

The world has been changing so fast. Meanwhile, mental health conditions should be taken as a serious issue. One of the psychological symptoms felt by the community is Anxiety Disorder. Changes in mental health 
conditions can be influenced by internal and external factors. Gradually, a lot of people are aware of the importance of mental health and are no longer afraid to speak up for what they feel. Anxiety disorder is a mental health disorder that causes the victims to have excessive anxiety followed by fear and worry about something that will affect their daily activities. It can suddenly attack people under certain circumstances [5]. This research has been conducted to diagnose anxiety disorders earlier by using a mobile application with an expert system and artificial intelligence inside. The expert system requires knowledge that comes from experts in the psychology field. The data that has been obtained will be processed and will yield the results in the form of classification of anxiety types using the Certainty Factor method and Naïve Bayes algorithm. The system will give some suggestions on what people need to do, such as individual exercises or therapies for an early remedy before meeting the therapist should the condition does not come better.

The solution to the fundamental problems previously discussed is answered by building a mobile application to diagnose anxiety disorders using Artificial Intelligence through the Certainty Factor method and Naïve Bayes algorithm based on the symptoms. This research is only limited to the analysis of the mental health condition in the scope of anxiety comorbid disorders type. The purpose of this research is to build a system that can be accessed by users to have diagnosed as early as possible in terms of anxiety disorders and then to give some suggestions for individual exercise or therapy. If the condition does not get better, then the experts are going to wait to meet this patient. The expert system that has been developed achieves an accuracy percentage of $96 \%$, whereas the application accuracy is $100 \%$ for the validity and reliability test.

\section{METHOD}

Expert system in artificial intelligence is very popular in helping expertise when diagnosing or giving decision support system in many fields. It is not to replace human expertise but to support and empower their work [6]. Some other researches that use expert systems were Hand, Mouth, and Foot Disease detection through a smartphone using the C4.5 method [7]. This disease can also be detected using image processing and the Certainty Factor method [8] and Naïve Bayes [9] for better accuracy. Because of those good preliminary researches, the Mental Health Helper application was developed using those methods for a better result in accuracy and performance. The previous researches only detected two types of diseases using the same methods, while this research can result in 4 types of diagnosis with more symptoms analysis.

\subsection{Anxiety Disorder}

Anxiety is known from psychological literature as a psychological condition with the main characteristics of which are phobias, tension, fear, and bad thoughts. Early detection of anxiety from physiological signals means a lot in the health care system for a better life not only for the sufferer but also for people around. Anxiety has negative valence so that it keeps individuals staying on negative thoughts and emotions [10]. Anxiety disorders include disorders that share excessive fear and anxiety, as well as related behavioral disorders. Fear is an emotional response to a real or perceived threat, whereas anxiety is an expectation of a future threat. These two situations overlap but are also different. Many anxiety disorders develop during childhood, and this covid-19 pandemic era makes it worse. If it is untreated, it tends to continue. Table 1 shows types of mental disorders with comorbid anxiety disorders that will be diagnosed [4].

Table 1. Type of Anxiety Disorder

\begin{tabular}{cc}
\hline Code of Disorder & Name of Disorder \\
\hline GG1 & Social Phobia Disorder (GFS) \\
\hline GG2 & Generalized Anxiety Disorder (GAM) \\
\hline GG3 & Panic Disorder (GP) \\
\hline GG4 & Obsessive-Compulsive Disorder (GOK) \\
\hline
\end{tabular}

Social phobia disorder can be described in one or more social situations, for example, having a conversation, meeting unfamiliar people, being observed (e.g., eating or drinking), and performing in front of others. The individual fears that he or she will be negatively evaluated. The generalized disorder is an excessive worry and anxiety (apprehensive expectation) occurring more days (at least six months) about a number of events or activities. Panic disorder is a sudden spike of intense fear or intense discomfort that reaches a peak within minutes. About four physical and cognitive symptoms occur. Obsessions are thoughts that repeat themselves over and over, and compulsions are usually performed in response to an obsession.

\subsection{Expert System}

One part of artificial intelligence is an expert system, which is a system that incorporates human knowledge or an expert [11]. The aim is to imitate the way an expert makes decisions [12]. An expert is 
someone who has the ability in a particular field who can solve a problem in this study, like a psychologist. Problem-solving carried out with the help of expert systems can be used by the realm of knowledge in certain fields [13]. Expert system technology can include certain languages, programs, and hardware selected for internal additions in the development and manufacture of expert systems [14].

\subsection{Certainty Factor}

Certainty theory is a framework for measuring and representing the level of confidence, whether it is true or false, in a knowledge-based system. Certainty theory rests on the Certainty Factor (CF). CF (Certainty Factor) is a method that states a measure of certainty against facts or rules to show the expert's belief in the problems experienced [15], in other words representing the value of trust in facts or hypotheses based on evidence [16]. Certainty factor introduces the concept of belief and uncertainty, the formula is [17]:

$$
C F[P, E]=M B[P, E]-M D[P, E]
$$

Where CF is the Certainty Factor, $\mathrm{P}$ is Probability, E is Evidence (Fact), MD is the Measure of Disbelief, and $\mathrm{MB}$ is Measure of Belief. The single premise rule is

$$
C F[H, E]=C F[H] * C F[E]
$$

$\mathrm{CF}[\mathrm{H}, \mathrm{E}]=$ The certainty factor in the $\mathrm{H}$ hypothesis that is influenced by the fact $\mathrm{E}$. Which are $\mathrm{CF}[\mathrm{H}]$ is a measure of user confidence and $\mathrm{CF}[\mathrm{E}]$ is the measure of expert confidence. Similar conclusion is

$$
C F \text { combine }(C F 1 . C F 2)=C F 1+C F 2 *(1-C F 1)
$$

\subsection{Naïve Bayes}

Naive Bayes is an application of Bayes' theorem in classification using probability and statistics proposed by Thomas Bayes. In Naive Bayes, each attribute used is considered independent or unrelated to other attributes [18]. If there are two separate events in Bayes' theorem (e.g., A and B), this can be represented by the equation

$$
P(A \mid B)=\frac{P(B \mid A) \times P(A)}{P(B)}
$$

Where $\mathrm{A}$ is the data hypothesis is a specific class, $\mathrm{B}$ is data with unknown class, $\mathrm{P}(\mathrm{A} \mid \mathrm{B})$ is the probability of hypothesis $\mathrm{A}$ based on condition $\mathrm{B}$ (posterior probability), $\mathrm{P}(\mathrm{B} \mid \mathrm{A})$ is the Probability of $\mathrm{B}$ based on condition on hypothesis $\mathrm{A}, \mathrm{P}(\mathrm{A})$ is a probability of hypothesis $\mathrm{A}$ (prior probabilities), and $\mathrm{P}(\mathrm{B})$ is a probability of $\mathrm{B}$.

The elaboration of the Bayes theorem formula in (4) by using the multiplication rule will lead to more and more results with increasingly complex characteristics. Therefore, this is where the very high independence (naive) assumption is used that each clue is independent of the other. With these assumptions, it can be formulated as

$$
P(C \mid F)=P(f 1 \mid C) \cdot P(f 2 \mid C) \cdot P(f 3 \mid C) \ldots P(f n \mid C) \cdot P(C)
$$

The equation (5) is a model of Naïve Bayes that will be used for the classification process. The number of symptoms is equal to the sum of all symptom combinations multiplied by the number of categories available. Naïve Bayes Classifier assumes that the presence or absence of a feature in a class is not related to the presence or absence of other features in the same class. $P(C \mid F)$ means the probability of Class based on Feature- the features which are used defined by $f 1, f 2$, till $f n$.

\section{RESULTS AND DISCUSSION}

\subsection{System Overview}

In Fig. 1, when the user finishes the testing process, the system will start to carry out the calculation process using the Certainty Factor and Naïve Bayes method, then a diagnosis will appear in the form of an anxiety disorder. The system will start to calculate the CF of each answer as many as the existing questions and then will provide output in the form of CF values and diagnoses [19].

The user carries out the testing process, namely answering questions with six different answer options, and each symptom has its own weight. The next step is to calculate the CF value of the single premise using formula (2) and calculate the combined CF value using formula (3). The maximum value of the four diagnoses is the final result $[20]$. 


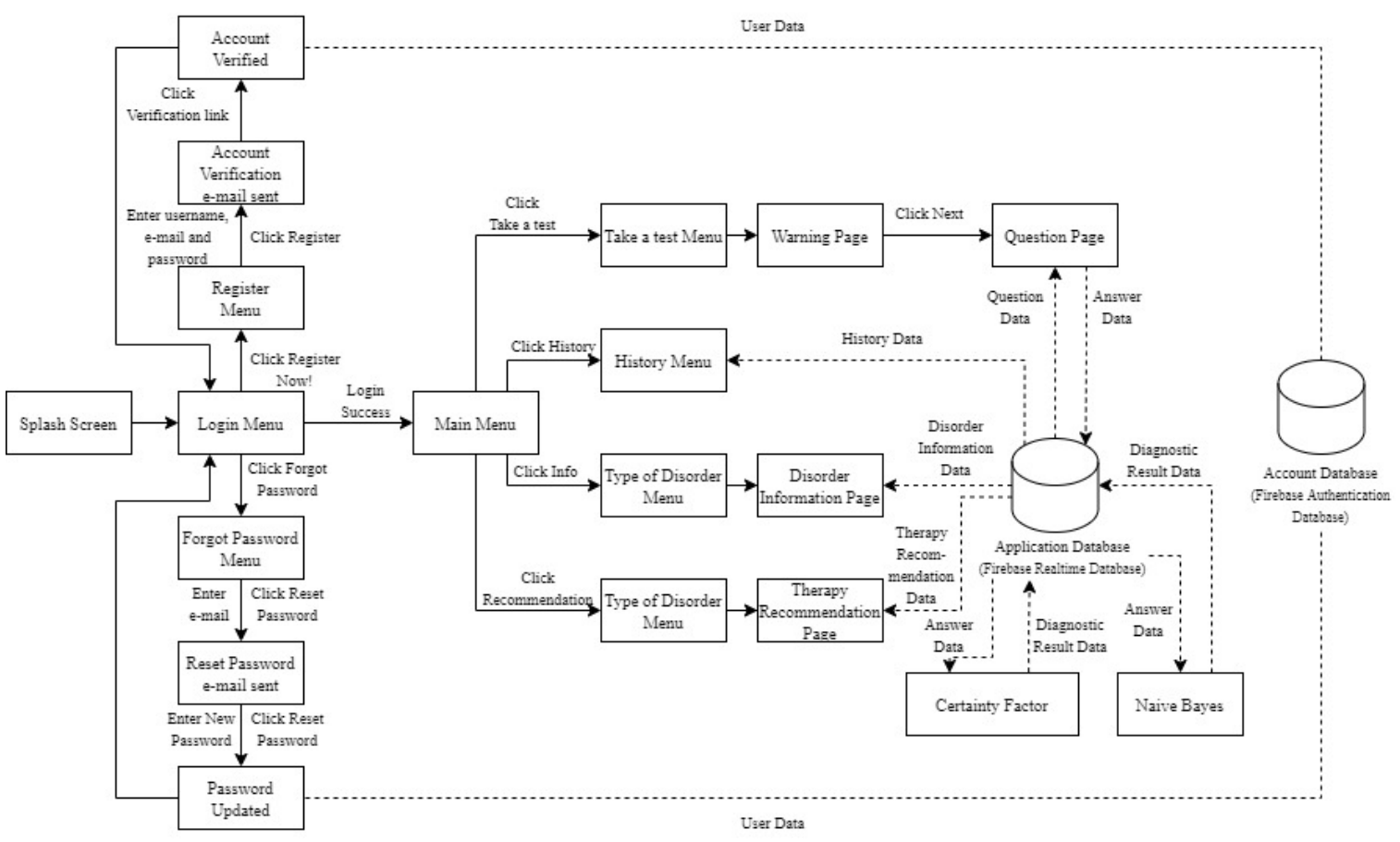

Fig. 1. System Overview

\subsection{Knowledge Base}

This research focuses on four comorbid anxiety disorders, namely Social Phobia Disorder (GFS), Generalized Anxiety Disorder (GAM), Panic Disorder (GP), and Obsessive-Compulsive Disorder (GOK), and uses 38 types of symptoms. The knowledge base of anxiety disorder symptoms in this research is shown in Table 2, and there are 38 types of symptoms in it. Anxiety symptoms are coded G followed by the symptom. These symptoms are obtained from the expert who mentioned in acknowledge.

\subsection{Steps of Certainty Factor Method}

The 38 symptoms are then grouped according to 4 types of anxiety disorders. Each symptom has a weight that contains an expert value depending on how influential the symptoms are for each category of disorder. The weight of symptoms can be seen in Table 3 .

The application of the Certainty Factor method to the system is based on the weight selected by the user [21]. In the application, the six answer options will be selected by the user during testing. Each answer choice contains a certain weight value for the certainty factor calculation process. The weight value of 1.0 is the highest and 0 the lowest. The more choices of answers with high weights, the higher the percentage of confidence values obtained [22]. The user's answer to the question about the symptoms experienced is one of the points that is included in the calculation process [13], and a decision is made regarding the assessment of the user's anxiety disorder condition [12]. The answers and their weighted values are shown in Table 4 and Table 5.

Based on the answer choices that have been entered by the user when doing the test, the data will be calculated using the CF value or Certainty Factor. The formula is listed in equations (2) and (3). The calculation process will be carried out as many as the number of anxiety disorders. According to this research, there are four disorders. Therefore, the system calculates the four disturbances, and then each result will be compared.

The expert value data and user input values will be calculated using the CF or Certainty Factor values with the formulas listed in equations (2) and (3), respectively. So that the following results are obtained, social Phobia Disorder is $14.436 \%$, Generalized Anxiety Disorder is 39.568\%, Panic Disorder is $80.24 \%$, ObsessiveCompulsive Disorder is $62.727 \%$. From the four calculation results before, the percentage value obtained from the lowest is Social Phobia Disorder (14.435\%), followed by Generalized Anxiety Disorder (39.568\%), then in the second place is Obsessive-Compulsive Disorder (62.727\%), and the highest is Panic Disorder with a percentage of $80.24 \%$. Thus, it can be concluded that the diagnosed anxiety disorder is Panic Disorder. 
Table 2. Symptoms of Anxiety

\begin{tabular}{|c|c|}
\hline Code & Symptoms of Anxiety \\
\hline G1 & Excessive anxiety and worry \\
\hline $\mathrm{G} 2$ & Unusual heartbeat/heart pounding \\
\hline G3 & Excessive sweating \\
\hline G4 & Body parts are shaking \\
\hline G5 & Difficulty concentrating \\
\hline G6 & Feeling worried and can't think clearly \\
\hline G7 & Avoidance of social situations \\
\hline G8 & Fear or anxiety when meeting new or unknown people \\
\hline G9 & The anxiety of being observed or judged by others \\
\hline G10 & Fear or anxiety in crowded situations or public spaces \\
\hline G11 & Exposure to the triggers causes muscles to feel tense or stiff or achy \\
\hline G12 & Exposure to the triggers causes frequent headaches or migraines \\
\hline G13 & Exposure to the triggers causes a panic attack \\
\hline G14 & Exposure to the triggers causes intense anxiety \\
\hline G15 & Dizzy \\
\hline G16 & Unable to breathe normally or breathless \\
\hline G17 & Always fell restless and thought unrealistically \\
\hline G18 & Uncontrollable worries \\
\hline G19 & $\begin{array}{l}\text { Experiencing three or more of the following: Impatience Easily Fatigue, Difficult to } \\
\text { concentrate, Irritability, Muscle Tension }\end{array}$ \\
\hline $\mathrm{G} 20$ & Easily shocked \\
\hline $\mathrm{G} 21$ & Stomach disturbances (e.g., constipation, nausea, abdominal pain) \\
\hline G22 & At least having experienced previous symptoms for the last six months \\
\hline $\mathrm{G} 23$ & Unlimited worry to specific objects \\
\hline G24 & It happens almost every day \\
\hline $\mathrm{G} 25$ & Inhabits most social functions (occupation, education, socialization) \\
\hline G26 & Unexpected recurring panic attacks \\
\hline G27 & At least feeling worried continuously around one month \\
\hline $\mathrm{G} 28$ & Panic feelings appear even though the triggering object doesn't harm \\
\hline G29 & Feeling the sensation of having a heart disease \\
\hline G30 & $\begin{array}{l}\text { Experiencing at least four of the following symptoms: abdominal pain, chest pain, chills, } \\
\text { dizziness, hot flushes, nausea, breathless, heart beating fast, sweating, and shaking }\end{array}$ \\
\hline G31 & $\begin{array}{l}\text { Experiencing at least one of the following symptoms: depersonalization, fear of losing } \\
\text { control, fear of going crazy, and fear of death }\end{array}$ \\
\hline G32 & Obsessions, recurring and persistent thoughts, impulses, or urges cause anxiety \\
\hline G33 & $\begin{array}{l}\text { Compulsions, repetitive physical and mental behaviors, and actions that the person did to } \\
\text { relieve tension }\end{array}$ \\
\hline G34 & $\begin{array}{l}\text { Obsessive thoughts, fear of getting dirty or getting sick, for example, avoiding shaking } \\
\text { hands with other people or touching objects that touch many people }\end{array}$ \\
\hline G35 & Obsessive mind, yearning for everything to be organized \\
\hline G36 & Compulsive thoughts, washing hands many times until blisters \\
\hline G37 & Compulsive thoughts, putting things in the same direction \\
\hline G38 & npulsive thoughts, repeatedly checking what has been don \\
\hline
\end{tabular}

\subsection{Steps of Naïve Bayes Method}

Calculation of the number of per-disorder data and their probabilities are shown [23]. The dataset used from the expert (psychologist) has 45 data with details and probability values, as shown in Table 6. Calculation of the amount of data per symptom and its probability is referred to [23] because there are zero probability values. Hence, we do Laplace correction and multiply all symptom probabilities thereafter based on case examples.

Multiplication of the symptom probability by the disorder probability is shown in Table 7 and Table 8 . Based on the example in Table 7 and Table 8 , it can be seen that the largest value of the multiplication result was obtained by GFS. Then, the example of case 1 tends to Social Phobia Disorder. The Naïve Bayes model has efficiency in estimating a wide range of probability density functions [24]. 

Vol. 7, No. 3, December 2021, pp. 479-490

\begin{tabular}{|c|c|c|c|c|}
\hline Code & GFS & GAM & GP & GOK \\
\hline G1 & 0.9 & 0.9 & 0.7 & 1 \\
\hline G2 & 0.8 & 0.9 & 0.9 & \\
\hline G3 & 0.8 & 0.6 & 0.9 & \\
\hline G4 & 0.9 & 0.9 & 0.9 & \\
\hline G5 & 0.7 & 0.8 & & \\
\hline G6 & 0.9 & & & \\
\hline G7 & 1 & & & \\
\hline G8 & 0.9 & & & \\
\hline G9 & 1 & & & \\
\hline G10 & 1 & 0.6 & 0.7 & \\
\hline G11 & 0.9 & 0.7 & & \\
\hline G12 & 0.7 & & & \\
\hline G13 & 0.8 & & & \\
\hline G14 & 0.9 & & & \\
\hline G15 & & 0.6 & 0.6 & \\
\hline G16 & & 0.7 & 0.8 & \\
\hline G17 & & 1 & & \\
\hline G18 & & 1 & & \\
\hline G19 & & 0.9 & & \\
\hline G20 & & 0.7 & & \\
\hline G21 & & 0.6 & 0.8 & \\
\hline G22 & & 1 & & \\
\hline G23 & & 1 & & \\
\hline G24 & & & & \\
\hline G25 & & & 0.9 & \\
\hline G26 & & & 1 & \\
\hline G27 & & & 0.9 & \\
\hline G28 & & & 0.9 & \\
\hline G29 & & & 0.8 & \\
\hline G30 & & & 0.9 & \\
\hline G31 & & & 0.9 & \\
\hline G32 & & & & 1 \\
\hline G33 & & & & 1 \\
\hline G34 & & & & 0.9 \\
\hline G35 & & & & 0.8 \\
\hline G36 & & & & 0.8 \\
\hline G37 & & & & 0.8 \\
\hline G38 & & & & 1 \\
\hline
\end{tabular}

Table 4. Weight of Answer

\begin{tabular}{cc}
\hline Answer & Weight \\
\hline Very often & 1.0 \\
\hline Often enough & 0.8 \\
\hline Often & 0.6 \\
\hline Rarely & 0.4 \\
\hline Doubt & 0.2 \\
\hline Never & 0 \\
\hline
\end{tabular}

\subsection{Application Design}

In developing this application, it needs a smartphone with Android 11 operating system with minimum RAM 4 GB, computer with minimum RAM 8 GB which are Android Studio 4.2.1 installed, Android Software Development Kit (SDK), Java Development Kit (JDK), Figma for User Interface design, Google Colab for engine reference, Firebase. Fig. 2 shows the mobile application screenshots. The main menu page consists of 
4 menus, namely the test menu, history, information, and recommendations. The figure is the description of the four menus. The test menu is a page to diagnose anxiety disorders with an expert system. The history menu contains the history of previous tests. The information menu contains brief information about anxiety disorders. The recommendation menu contains recommendations for handling anxiety disorders

Table 5. Weight of User's Answer

\begin{tabular}{cccccccc}
\hline $\begin{array}{c}\text { Symptom } \\
\text { Code }\end{array}$ & $\begin{array}{c}\text { User } \\
\text { Value }\end{array}$ & $\begin{array}{c}\text { Symptom } \\
\text { Code }\end{array}$ & $\begin{array}{c}\text { User } \\
\text { Value }\end{array}$ & $\begin{array}{c}\text { Symptom } \\
\text { Code }\end{array}$ & $\begin{array}{c}\text { User } \\
\text { Value }\end{array}$ & $\begin{array}{c}\text { Symptom } \\
\text { Code }\end{array}$ & $\begin{array}{c}\text { User } \\
\text { Value }\end{array}$ \\
\hline G1 & 1 & G11 & 0.2 & G21 & 0.4 & G31 & 1 \\
\hline G2 & 0.4 & G12 & 0 & G22 & 0.6 & G32 & 1 \\
\hline G3 & 0.4 & G13 & 0 & G23 & 0.4 & G33 & 1 \\
\hline G4 & 0.4 & G14 & 0 & G24 & 0 & G34 & 1 \\
\hline G5 & 0.4 & G15 & 0 & G25 & 1 & G35 & 1 \\
\hline G6 & 0.4 & G16 & 0.4 & G26 & 1 & G36 & 1 \\
\hline G7 & 0.4 & G17 & 0.4 & G27 & 1 & G37 & 1 \\
\hline G8 & 0.2 & G18 & 0.4 & G28 & 0.4 & G38 & 1 \\
\hline G9 & 0.2 & G19 & 0.4 & G29 & 1 & & \\
\hline G10 & 0.2 & G20 & 0.2 & G30 & 1 & & \\
\hline
\end{tabular}

Table 6. Disorder Probability

\begin{tabular}{ccc}
\hline Disorder Code & Data Total & Probability \\
\hline $\mathrm{P}(\mathrm{GAM})$ & 6 & 0.133333 \\
\hline $\mathrm{P}(\mathrm{GFS})$ & 28 & 0.622222 \\
\hline $\mathrm{P}(\mathrm{GOK})$ & 4 & 0.088889 \\
\hline $\mathrm{P}(\mathrm{GP})$ & 7 & 0.155556 \\
\hline
\end{tabular}

Table 7. Result of Symptom Probability Multiplication

\begin{tabular}{ccccc}
\hline Calculation & P(ai|GAM) & P(ai|GFS) & P(ai|GOK) & P(ai|GP) \\
\cline { 2 - 5 } P(ai|Gi) & $3.22188 \mathrm{E}-40$ & $1.78648 \mathrm{E}-37$ & $1.52099 \mathrm{E}-48$ & $1.09345 \mathrm{E}-44$ \\
\hline
\end{tabular}

Table 8. Multiplication Result of Symptom Probability and Disorder Probability

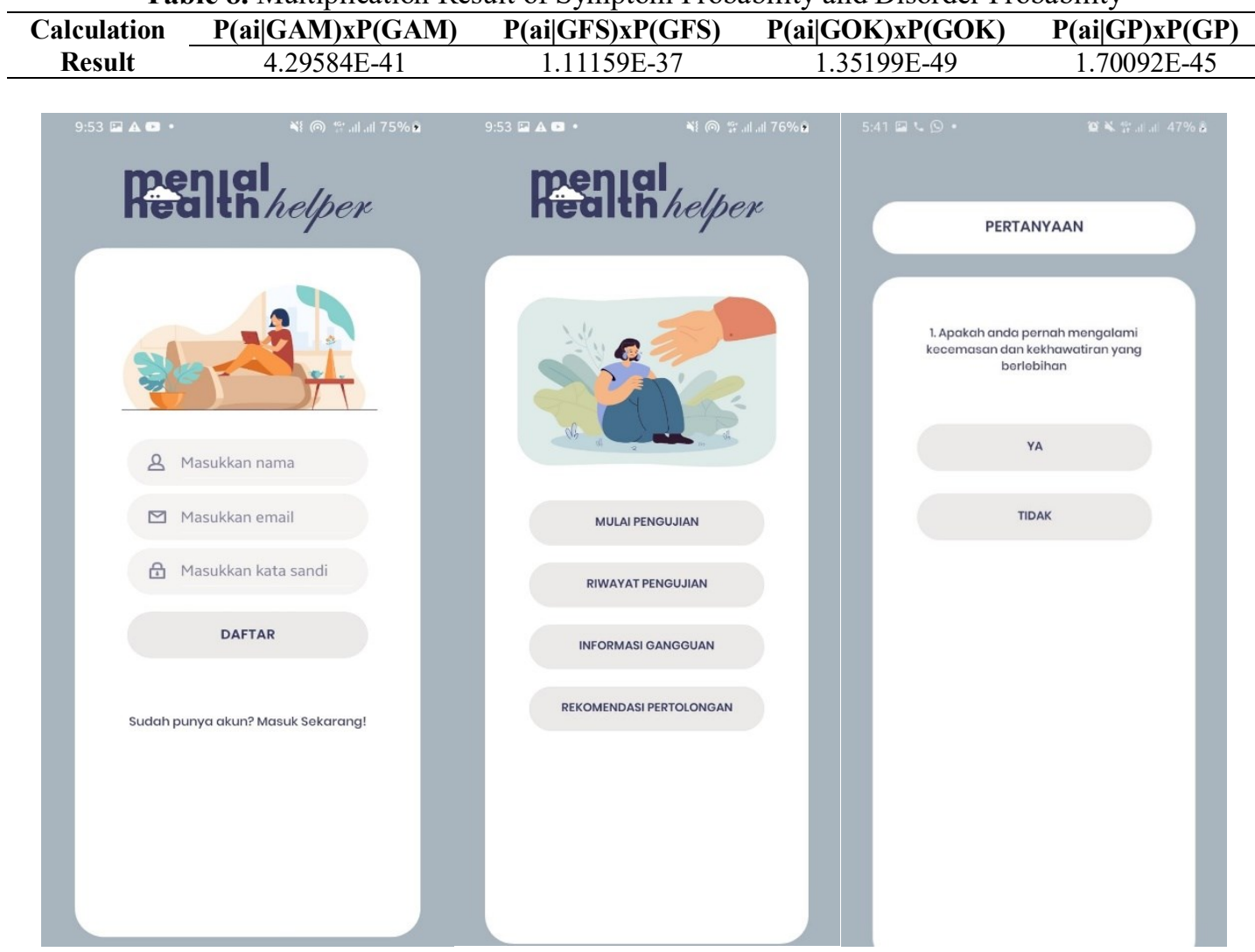

Fig. 2. Mobile application screenshots 


\subsection{Testing Result}

This test is carried out by comparing the results obtained from the system with expert results. In the testing process, the dataset will be divided into 2, namely training and testing data. Fig. 3 is the accuracy for each data partition test.

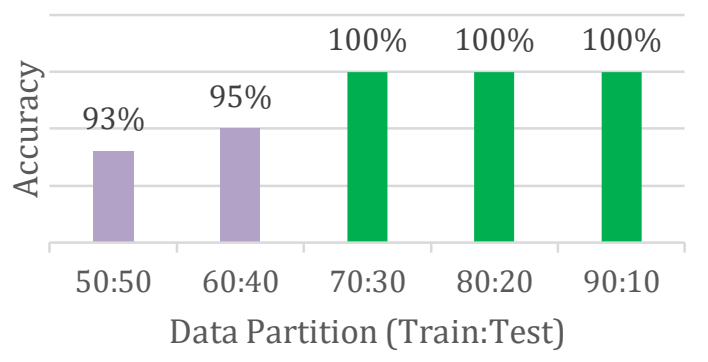

Fig. 3. Testing Accuracy of Data Partition

Based on Fig. 3, it can be seen that the data partition test with a ratio of 50:50 got an accuracy of $93 \%$, 60:40 got an accuracy of 95\%, and 70:30, 80:20, and 90:10 got an accuracy value of $100 \%$. Because the test has good results, it is concluded that the dataset can be used for expert systems. In testing the accuracy of the system, scenario tests were carried out by comparing the results obtained from the system and expert conclusions [25]. From this process, it can be seen how accurate the system is. The results of the system test for 50 data are shown in Table 9. The CF value in the second column is the Certainty Factor value or the final result of the system test.

Based on Table 9, from the 50 data tested, it is known that 48 data showed the same results as the results of expert diagnoses with appropriate information. To calculate the accuracy of all data, the formula is used, namely the number of correct values divided by the number of test data multiplied by $100 \%$. Here is the formula for calculating the accuracy value. Thus, the percentage of system accuracy is $96 \%$.

$$
\frac{48}{50} \times 100 \%=96 \%
$$

The use of the Naïve Bayes method on the expert system has an average accuracy of $96 \%$ (Table 10). It has similar accuracy to the Certainty Factor method, so both of these methods are very good to use in the expert system as early diagnose of anxiety disorder. The expert system processes and analyzes medical information to identify groups of patients very well [26].

\subsection{Validity and Reliability Testing}

The technique that can be used to determine validity is the product-moment correlation technique by Pearson with the following equation [27][28]:

$$
r_{\text {count }}=\frac{N \Sigma A B-\Sigma A \Sigma B}{\sqrt{\Sigma A^{2}(\Sigma A)^{2} N \Sigma B^{2}(\Sigma B)^{2}}}
$$

Where $r_{\text {count }}$ is correlation coefficient, $\mathrm{N}$ is the Number of Respondents, $\mathrm{A}$ is the Item score per respondent, and $\mathrm{B}$ is the total score per respondent.

If the value of R_count $>\mathrm{R}$ _table, then the question can be said to be valid. On the other hand, if R_count $<\mathrm{R}$ table, the question is invalid. From the 50 respondents in Table 11, we can conclude the survey to the user of this application is valid.

Reliability testing aims to determine whether the application testing can be justified. This test is done by calculating the alpha coefficient or Cronbach's Alpha for each question. The test aims to determine whether the test results will be consistent if done repeatedly. This test was chosen because it is common and only needs one test. The equation used is [29]:

$$
r_{11}=\left[\frac{k}{k-1}\right]\left[1-\frac{\Sigma \sigma^{2} b}{\sigma^{2} t}\right]
$$

Where $r_{11}$ is Alpha reliability coefficient, $\mathrm{k}$ is the Number of questions, $\Sigma \sigma^{2} b$ is the Number of item variance, and $\sigma^{2} t$ is total variances. 
Table 9. Accuracy Testing of Certainty Factor Method

\begin{tabular}{|c|c|c|c|c|}
\hline No & CF Value & System Results & Expert Results & Match \\
\hline 1 & $89.92 \%$ & Social Phobia Disorder & Social Phobia Disorder & Yes \\
\hline 2 & $76 \%$ & Social Phobia Disorder & Social Phobia Disorder & Yes \\
\hline 3 & $90.80 \%$ & Social Phobia Disorder & Social Phobia Disorder & Yes \\
\hline 4 & $89.92 \%$ & Social Phobia Disorder & Social Phobia Disorder & Yes \\
\hline 5 & $89.92 \%$ & Social Phobia Disorder & Social Phobia Disorder & Yes \\
\hline 6 & $87.68 \%$ & Social Phobia Disorder & Social Phobia Disorder & Yes \\
\hline 7 & $98 \%$ & Social Phobia Disorder & Social Phobia Disorder & Yes \\
\hline 8 & $76.08 \%$ & Social Phobia Disorder & Social Phobia Disorder & Yes \\
\hline 9 & $98 \%$ & Social Phobia Disorder & Social Phobia Disorder & Yes \\
\hline 10 & $97 \%$ & Social Phobia Disorder & Social Phobia Disorder & Yes \\
\hline 11 & $62.88 \%$ & Social Phobia Disorder & Social Phobia Disorder & Yes \\
\hline 12 & $89.92 \%$ & Social Phobia Disorder & Social Phobia Disorder & Yes \\
\hline 13 & $90.80 \%$ & Social Phobia Disorder & Social Phobia Disorder & Yes \\
\hline 14 & $96 \%$ & Generalized Anxiety Disorder & Generalized Anxiety Disorder & Yes \\
\hline 15 & $70.56 \%$ & Social Phobia Disorder & Social Phobia Disorder & Yes \\
\hline 16 & $84 \%$ & Generalized Anxiety Disorder & Generalized Anxiety Disorder & Yes \\
\hline 17 & $100 \%$ & Generalized Anxiety Disorder & Generalized Anxiety Disorder & Yes \\
\hline 18 & $96 \%$ & Generalized Anxiety Disorder & Generalized Anxiety Disorder & Yes \\
\hline 19 & $76 \%$ & Generalized Anxiety Disorder & Generalized Anxiety Disorder & Yes \\
\hline 20 & $100 \%$ & Generalized Anxiety Disorder & Generalized Anxiety Disorder & Yes \\
\hline 21 & $96 \%$ & Generalized Anxiety Disorder & Generalized Anxiety Disorder & No \\
\hline 22 & $96 \%$ & Generalized Anxiety Disorder & Generalized Anxiety Disorder & Yes \\
\hline 23 & $64 \%$ & Generalized Anxiety Disorder & Generalized Anxiety Disorder & Yes \\
\hline 24 & $84 \%$ & Generalized Anxiety Disorder & Generalized Anxiety Disorder & Yes \\
\hline 25 & $74.40 \%$ & Generalized Anxiety Disorder & Generalized Anxiety Disorder & Yes \\
\hline 26 & $98 \%$ & Generalized Anxiety Disorder & Generalized Anxiety Disorder & Yes \\
\hline 27 & $84 \%$ & Generalized Anxiety Disorder & Generalized Anxiety Disorder & Yes \\
\hline 28 & $96 \%$ & Generalized Anxiety Disorder & Generalized Anxiety Disorder & Yes \\
\hline 29 & $53.22 \%$ & Generalized Anxiety Disorder & Generalized Anxiety Disorder & No \\
\hline 30 & $99 \%$ & Panic Disorder & Panic Disorder & Yes \\
\hline 31 & $99 \%$ & Panic Disorder & Panic Disorder & Yes \\
\hline 32 & $85.44 \%$ & Panic Disorder & Panic Disorder & Yes \\
\hline 33 & $70.56 \%$ & Panic Disorder & Panic Disorder & Yes \\
\hline 34 & $92.16 \%$ & Panic Disorder & Panic Disorder & Yes \\
\hline 35 & $97.20 \%$ & Panic Disorder & Panic Disorder & Yes \\
\hline 36 & $92.16 \%$ & Panic Disorder & Panic Disorder & Yes \\
\hline 37 & $89.92 \%$ & Panic Disorder & Panic Disorder & Yes \\
\hline 38 & $97.20 \%$ & Panic Disorder & Panic Disorder & Yes \\
\hline 39 & $81.60 \%$ & Panic Disorder & Panic Disorder & Yes \\
\hline 40 & $99 \%$ & Panic Disorder & Panic Disorder & Yes \\
\hline 41 & $77 \%$ & Panic Disorder & Panic Disorder & Yes \\
\hline 42 & $97 \%$ & Panic Disorder & Panic Disorder & Yes \\
\hline 43 & $100 \%$ & Obsessive-Compulsive Disorder & Obsessive-Compulsive Disorder & Yes \\
\hline 44 & $100 \%$ & Obsessive-Compulsive Disorder & Obsessive-Compulsive Disorder & Yes \\
\hline 45 & $96 \%$ & Obsessive-Compulsive Disorder & Obsessive-Compulsive Disorder & Yes \\
\hline 46 & $92.80 \%$ & Obsessive-Compulsive Disorder & Obsessive-Compulsive Disorder & Yes \\
\hline 47 & $100 \%$ & Obsessive-Compulsive Disorder & Obsessive-Compulsive Disorder & Yes \\
\hline 48 & $100 \%$ & Obsessive-Compulsive Disorder & Obsessive-Compulsive Disorder & Yes \\
\hline 49 & $92.80 \%$ & Obsessive-Compulsive Disorder & Obsessive-Compulsive Disorder & Yes \\
\hline 50 & $100 \%$ & Obsessive-Compulsive Disorder & Obsessive-Compulsive Disorder & Yes \\
\hline
\end{tabular}

Table 10. Accuracy Testing of Naïve Bayes Method

\begin{tabular}{cccc}
\hline Disorders & Match & Mismatch & Percentage \\
\hline GAM & 6 & 1 & $86 \%$ \\
\hline GFS & 32 & 0 & $100 \%$ \\
\hline GOK & 5 & 0 & $100 \%$ \\
\hline GP & 8 & 1 & $89 \%$ \\
\hline
\end{tabular}


Table 11. Validity Test Result

\begin{tabular}{cccc}
\hline Question Number & R_count & R_table & Status \\
\hline 1 & 0.690 & 0.268 & Valid \\
\hline 2 & 0.710 & 0.268 & Valid \\
\hline 3 & 0.673 & 0.268 & Valid \\
\hline 4 & 0.754 & 0.268 & Valid \\
\hline 5 & 0.805 & 0.268 & Valid \\
\hline 6 & 0.830 & 0.268 & Valid \\
\hline 7 & 0.700 & 0.268 & Valid \\
\hline 8 & 0.567 & 0.268 & Valid \\
\hline 9 & 0.761 & 0.268 & Valid \\
\hline 10 & 0.467 & 0.268 & Valid \\
\hline
\end{tabular}

$\mathrm{R}_{11}$ value will be compared to $\mathrm{R}$ _table value such as validity testing. If the value of $r_{11}>\mathrm{R}$ _table, then the questionnaire will be considered reliable. Meanwhile, if the value of $r_{11}<\mathrm{R}$ table, the questionnaire is considered unreliable [30]. Table 12 shows the results of reliability testing. From the 50 respondents in Table 12 and based on the calculation result, $r_{11}>R_{-}$table, then we can conclude the survey to the user of this application is reliable.

Table 12. Reliability Test Result

\begin{tabular}{ccccc}
\hline Number of Each Variance & Number of Total Variances & $\mathbf{r}_{\mathbf{1 1}}$ & R_table & Conclusion \\
\hline 4.690426275 & 22.77009085 & 0.882232589 & 0.268 & Reliable \\
\hline
\end{tabular}

\section{CONCLUSION}

This research used four types of mental disorders with anxiety disorders comorbid. There are Social Phobia Disorder, Generalized Anxiety Disorder, Panic Disorder, and Obsessive-Compulsive Disorder. These disorders have many symptoms grouped based on the effect on each anxiety disorder. After analyzing and testing this expert system, we concluded that the application could display the results of the diagnosis of anxiety disorders based on the answers selected by the user during the testing process using the Certainty Factor and Naïve Bayes method. They have an accuracy rate of $96 \%$. The success of the system in diagnosing is very dependent on the knowledge base that is built with the expertise. Mismatch in diagnosing the disease is reasonable if the weights of each symptom are inappropriate given by expertise. This application has validity and reliability test, and they prove this application are valid and reliable. For further study, the system can be developed smarter and more intelligent by self-generate the weight of each symptom. The system can adapt to new input from the users and generate the weight corresponding to the input pattern.

\section{Acknowledgment}

The authors express her gratitude to Mrs. Trie Nurfadillah Hanapi, M.Psi., Psikolog, who has helped the authors invalidate the anxiety disorder data that the authors' used. This application is in the process of intellectual property registration by Telkom University.

\section{REFERENCES}

[1] F. Kaligis, M. T. Indraswari, and R. I. Ismail, "Stress during COVID-19 pandemic: mental health condition in Indonesia," Medical Journal of Indonesia, vol. 29, no. 4, pp. 436-41, 2020. https://doi.org/10.13181/mji.bc.204640

[2] P. M. Doraiswamy, C. Fox and J. Gordon, "How the Pandemic Is Changing Mental Health," Scientific American, 14 September 2021. https://www.scientificamerican.com/article/how-the-pandemic-is-changing-mental-health/

[3] SZ Zhao, JYH Wong, Y Wu, EPH Choi, Wang MP, and Lam TH, "Social Distancing Compliance under COVID-19 Pandemic and Mental Health Impacts: A Population-Based Study," International Journal of Environmental Research and Public Health, vol. 17, no. 18, p. 6692, 2020. https://doi.org/10.3390/ijerph17186692

[4] P. A. Association, Diagnostic and Statistical Manual of Mental Disorders, Fifth Edition (DSM-5), United States of America: American Psychiatric Publishing, 2013.

[5] A. Papić, A. Hefer, and T. Krstanović, "Information Anxiety: Research Among Students About Impact of Different Media On Them," MIPRO 2012 - 35th Int. Conv. Inf. Commun. Technol. Electron. Microelectron. - Proc., pp. 12441248, 2012. https://ieeexplore.iee.org/abstract/document/6240827

[6] J. Alrassi, P. J. Katsufrakis, and L. Chandran, "Technology Can Augment, but Not Replace, Critical Human Skills Needed for Patient Care," Academic Medicine, vol. 96, no. 1, pp. 37-43, 2020. https://doi.org/10.1097/ACM.0000000000003733

[7] F. H. Syahrial, B. Irawan, and A. L. Prasasti, "Detecting Hand, Foot and Mouth Disease in Earlier Stage Using C4. 5 Algorithm as Expert System Based on Android," In Journal of Physics: Conference Series, vol. 1201, no. 1, p. 012059, IOP Publishing, 2019. https://doi.org/10.1088/1742-6596/1201/1/012059 
[8] D. Novitasari, B. Irawan, and A. L. Prasasti, "Early Detection of Hand, Foot, and Mouth Disease based on Palmprint using Certainty Factor as Expert System Method based on Android," In Journal of Physics: Conference Series, vol. 1201, no. 1, p. 012055, IOP Publishing, 2019. https://doi.org/10.1088/1742-6596/1201/1/012055

[9] F. A. R. F. Rizki, B. Irawan, and A. L. Prasasti, "Deteksi Hand, Foot, and Mouth Disease Menggunakan Metode Klasifikasi Naïve Bayes Berbasis Android," In Seminar Nasional Teknologi Komputer \& Sains (SAINTEKS), vol. 1, no. 1, 2019. http://seminar-id.com/prosiding/index.php/sainteks/article/view/225

[10] M. A. Adheena, N. Sindhu, and S. Jerritta, "Physiological Detection of Anxiety," 2018 Int. Conf. Circuits Syst. Digit. Enterp. Technol. ICCSDET 2018, pp. 1-5, 2018. https://doi.org/10.1109/ICCSDET.2018.8821162

[11] Ana, A. (2020). Trends in expert system development: A practicum content analysis in vocational education for over grow pandemic learning problems," Indonesian Journal of Science and Technology, vol. 5, no. 2, 246-260. https://doi.org/10.17509/ijost.v5i2.24616

[12] R. Fulmer, A. Joerin, B. Gentile, L. Lakerink, and M. Rauws, "Using psychological artificial intelligence (Tess) to relieve symptoms of depression and anxiety: randomized controlled trial," JMIR mental health vol. 5, no. 4, p. e64, 2018. https://doi.org/10.2196/mental.9782

[13] A. Andriani, A. Meyliana, Sardiarinto, W. E. Susanto, and SupriYesnta, "Certainty Factors in Expert System to Diagnose Disease of Chili Plants," 2018 6th Int. Conf. Cyber IT Serv. Manag. CITSM 2018, no. Citsm, pp. 1-6, 2019. https://doi.org/10.1109/CITSM.2018.8674264

[14] B. S. Adamczyk, A. L. Szejka, and O. C. Júnior, "Knowledge-based expert system to support the semantic interoperability in smart manufacturing," Computers in Industry, vol. 115, p. 103161, 2020. https://doi.org/10.1016/j.compind.2019.103161

[15] D. Kiray, and F. A. Sianturi, "Diagnose Expert System Computer Malfunction Certainty Factor Method," Journal of Computer Networks, Architecture, and High-Performance Computing, vol. 2, no. 1, pp. 63-71, 2020. https://doi.org/10.47709/cnapc.v2i1.358

[16] S. Santhoshkumar and L. D. Babu, "Earlier detection of rumors in online social networks using certainty-factor-based convolutional neural networks," Social Network Analysis and Mining, vol. 10, no. 1, pp. 1-17, 2020. https://doi.org/10.1007/s13278-020-00634-x

[17] Laurentinus, Kiswanto, R. Sulaiman, F. P. Juniawan, D. Y. Sylfania, P. Kurniawan, and H. A. Pradana, "Design Fuzzy Expert System And Certainty Factor In Early Detection Of Stroke Disease," In 2020 8th International Conference on Cyber and IT Service Management (CITSM), pp. 1-7, IEEE, 2020. https://doi.org/10.1109/CITSM50537.2020.9268830

[18] I. Wickramasinghe, and H. Kalutarage, "Naive Bayes: applications, variations and vulnerabilities: a review of literature with code snippets for implementation," Soft Computing, vol. 25, no. 3, pp. 2277-2293, 2021. https://doi.org/10.1007/s00500-020-05297-6

[19] A. A. N. Purnomo, S. Andryana, and A. Iskandar, "Application of Expert System for Diagnosing Gastric Disease Android Based with Certainty Factor Method," Jurnal Teknik Informatika CIT Medicom, vol. 12, no. 1, pp. 7-15, 2020.

[20] K. Ain, H. B. Hidayati, and O. A. Nastiti, "Expert System for Stroke Classification Using Naive Bayes Classifier and Certainty Factor as Diagnosis Supporting Device," In Journal of Physics: Conference Series, vol. 1445, no. 1, p. 012026, IOP Publishing. https://doi.org/10.1088/1742-6596/1445/1/012026

[21] H. Fonda, M. Ikhsanudin, and Y. Irawan, "Application Of Certainty Factor Method To Identify Pests In Crystal Jamboo Plants," In Journal of Physics: Conference Series, vol. 1783, no. 1, p. 012053, IOP Publishing, 2021. https://doi.org/10.1088/1742-6596/1783/1/012053

[22] I. Sumatorno, D. Arisandi, A. P. U. Siahaan, and M. Mesran, "Expert System of Catfish Disease Determinant Using Certainty Factor Method," International Journal of Recent Trends in Engineering \& Research, vol. 3, no. 8, 2017. https://doi.org/10.23883/IJRTER.2017.3405.TCYZ2

[23] S. Chen, G. I. Webb, L. Liu, and Xin Ma, "A novel selective naïve Bayes algorithm," Knowledge-Based Systems, vol. 192, p. 105361, 2020. https://doi.org/10.1016/j.knosys.2019.105361

[24] A. Khajenezhad, M. A. Bashiri, and H. Beigy, "A distributed density estimation algorithm and its application to naive Bayes classification," Applied Soft Computing, vol. 98, 106837, 2021. https://doi.org/10.1016/j.asoc.2020.106837

[25] D. A. Kurniawan and S. W. Sihwi, "An expert system for diagnosing dysgraphia," In 2017 2nd International conferences on Information Technology, Information Systems and Electrical Engineering (ICITISEE), pp. 468-472, IEEE, 2017. https://doi.org/10.1109/ICITISEE.2017.8285552

[26] E. Chebanenko, L. Denisova, and A. Serobabov, "Intelligent Processing of Medical Information for Application in the Expert system," In 2020 Ural Symposium on Biomedical Engineering, Radioelectronics and Information Technology (USBEREIT), pp. 0085-0088, IEEE, 2020. https://doi.org/10.1109/USBEREIT48449.2020.9117723

[27] L. Cohen, L. Manion, and K. Morrison, "Validity and reliability," In Research methods in education, pp. 245-284, Routledge, 2017. https://doi.org/10.4324/9781315456539-14

[28] H. K. Mohajan, "Two criteria for good measurements in research: Validity and reliability," Annals of Spiru Haret University, Economic Series, vol. 17, no. 4, pp. 59-82, 2017. https://doi.org/10.26458/1746

[29] A. G. Silva, P. Simões, A. Queirós, M. Rodrigues, and N. P. Rocha, "Mobile apps to quantify aspects of physical activity: a systematic review on its reliability and validity," Journal of medical systems, vol. 44, no. 2, pp. 1-19, 2020. https://doi.org/10.1007/s10916-019-1506-z

[30] C. Livas, K. Delli, F. K. Spijkervet, A. Vissink, and P. U. Dijkstra, "Concurrent validity and reliability of cephalometric analysis using smartphone apps and computer software," The Angle Orthodontist, vol. 89, no. 6, pp. 889-896, 2019. https://doi.org/10.2319/021919-124.1 


\section{BIOGRAPHY OF AUTHORS}

Anggunmeka Luhur Prasasti (born in Pasuruan, 1990) received her Engineering degree in Telecommunication Engineering from Telkom Institute of Technology (Telkom University) in 2012. She obtained her master's degree in the Biomedical Engineering Program from the School of Electrical Engineering and Informatics, Institut Teknologi Bandung, in 2015. Her current research interests are artificial intelligence in signal processing and machine learning implementation to detect any kind of disease, forecast conditions such as rain possibility, and crowd density in an area. She's used to competing in several international IT competitions such as Microsoft Imagine Cup and Asia Pacific ICT Awards, to name a few. She could be reached through email: anggunmeka@telkomuniversity.ac.id

Iftitahrira Aulia Rahmi (born in Kisaran, 1999) received her Engineering degree in Computer Engineering from Telkom University in 2021. Her final project in bachelor's degree is about expert systems. She is concerned about learning more things about expert systems and designing UI/UX. She could be reached through email: iftitahriraa@student.telkomuniversity.ac.id

Syarifah Faisa Nurahmani was born on November $18^{\text {th }}, 1999$, in Jakarta. She graduated from Telkom University with a Bachelor's Degree in Computer Engineering this year. Her final project was about android application development and expert system. She wants to learn more about application development and artificial intelligence. Email: syarifahfaisa@student.telkomuniversity.ac.id

Ashri Dinimaharawati (born in Bandung, 1993) received her Education degree in Computer Science Education from the Indonesia University of Education in 2015. She obtained her master's degree in Electrical Engineering from the School of Electrical Engineering and Informatics, Institut Teknologi Bandung, in 2018. Her current research interests are games development and programming. She's used to competing in several national competitions, such as the Line dev competition. She could be reached through email: ashridini@telkomuniversity.ac.id 